\title{
Pacto Federativo e o Plano de Cargos, Carreira e Remuneração dos Profissionais da Educação: o caso do estado do Pará
}

\author{
Rosana Maria Oliveira Gemaque ${ }^{1}$ \\ Bruno Cordovil Picanço ${ }^{2}$ \\ Danielle Cristina de Brito Mendes ${ }^{3}$ \\ dany.britto@hotmail.com
}

\section{Resumo}

Atualmente há um retorno aos debates sobre o modelo federativo e as possibilidades e configurações de pacto entre os entes federados no que concerne ao provimento da educação pública. Nesse sentido, o texto objetiva analisar as possibilidades de pacto entre os entes federados em educação, a partir da análise do processo de elaboração e de negociações sobre o Plano de Cargos, Carreira e Remuneração (PCCR) do magistério no Estado do Pará. A análise processa-se no cotejamento entre as Diretrizes Nacionais para os PCCRs fixadas pelo Conselho Nacional de Educação (CNE) e a proposta de plano do Sindicado dos Trabalhadores em Educação Pública do Estado do Pará (Sintepp) do Executivo e o produto final dessas, a lei n. 7.447/10. Concluímos que a definição de diretrizes para elaboração dos PCCRs se configura em medida incipiente para a efetivação do pacto federativo, e que a organização dos professores por meio do sindicato no

\footnotetext{
1 Doutora em Educação pela Universidade de São Paulo (2004); professora do Instituto de Ciências da Educação da Universidade Federal do Pará (UFPA); orientadora de mestrado e doutorado. 2 Pedagogo; aluno do Mestrado Acadêmico em Educação (UFPA); Bolsista INEP/CAPES. 3 Pedagoga; especialista em Educação Classe I da Secretaria Executiva de Educação do Estado do Pará; aluna do Mestrado Acadêmico em Educação (UFPA).
}

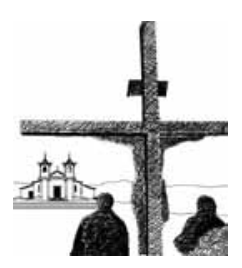

113 
processo de elaboração do PCCR do Estado do Pará foi fundamental para assegurar alguns avanços na direção da valorização do magistério.

Palavras-chave: Pacto federativo; educação básica; plano de cargos, carreira e remuneração.

\section{Introdução}

O texto apresenta discussões acerca das possibilidades de um "novo" pacto entre os entes federados na área da educação, a partir da análise das propostas de Plano de Cargos, Carreira e Remuneração (PCCR) do governo do Estado do Pará, do Sindicado dos Trabalhadores em Educação Pública do Estado do Pará (Sintepp) e do produto final dessas, a lei do PCCR dos Profissionais da Educação Básica da rede de ensino estadual (lei n. 7.442 de 02 de julho de 2010). Nossas análises cotejam-se com as Diretrizes Nacionais para os PCCRs dos Profissionais do Magistério da Educação Básica Pública de Ensino do Estado do Pará, fixadas pelo Conselho Nacional de Educação (CNE), por meio da Resolução n. 02 de 20 de maio de 2010.

Essa discussão é parte integrante de um conjunto de investigações que vêm sendo processadas no âmbito do projeto de pesquisa sobre a "Remuneração dos professores da rede pública da educação básica: configurações, impactos, impasses e perspectivas". O projeto objetiva analisar as configurações, os impactos, os impasses e as perspectivas decorrentes da implantação do Fundo de Manutenção e Desenvolvimento do Ensino Fundamental e de Valorização do Magistério (Fundef), do

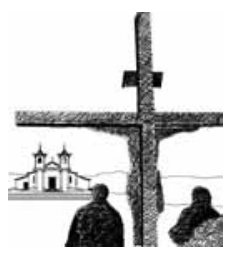

114 Fundo de Manutenção e Desenvolvimento da Educação Básica e de Valorização dos Profissionais da Educação (Fundeb) e do Piso Salarial Profissional Nacional (PSPN) na estrutura de remuneração dos professores da Educação Básica de dez estados brasileiros, no período de 1996 a 2010.

Focalizamos a discussão sobre o pacto federativo a partir de um ponto específico que são os PCCRs do Magistério Público da 
Educação Básica. Trata-se de um aspecto importante para discutir o pacto entre os entes federados, tendo em vista a heterogeneidade e complexidade envolta na situação da carreira e remuneração dos professores nos vinte e seis estados, um Distrito Federal e cerca de cinco mil e 565 municípios brasileiros, com regulamentações próprias.

Nessa direção, a questão central do texto consiste em discutirmos como se configura/expressa o pacto ou a possibilidade de pacto entre os entes federados acerca da educação a partir do PCCR do Magistério da Educação Básica?

Para tanto, analisamos as propostas de PCCR do Executivo do Estado do Pará juntamente com a proposta do Sintepp discutidas na Assembleia Legislativa do Estado do Pará (Alepa), bem como a lei n. 7.442/10 que regulamenta o PCCR dos Profissionais da Educação do Pará no cotejamento com as diretrizes nacionais para elaboração dos planos.

\section{Educação e federalismo}

Para Abrúcio, "o federalismo é uma forma de organização territorial do Estado e, como tal, tem enorme impacto na organização dos governos e na maneira como eles respondem aos cidadãos" (ABRÚCIO, 2010, p. 39). Além disso, o autor argumenta que nesse modelo, os entes federados gozam de autonomia e compartilham legitimidade no processo decisório sobre as políticas públicas. Por essa razão, é possível mais de um agente governamental atuar numa mesma direção em relação ao atendimento às demandas sociais, sendo, em alguns casos, pertinente a "ação conjunta e/ou a negociação entre os níveis de governo em questões condicionadas à interdependência entre eles" (ABRÚCIO, 2010, p. 39).

O princípio da autonomia, de acordo com a Constituição Federal de 1988 (CF/88), perpassa questões de ordem financeira, legislativa e administrativa em que os entes federados gozam de autonomia para arrecadar impostos, definir seus orçamentos e normatizar

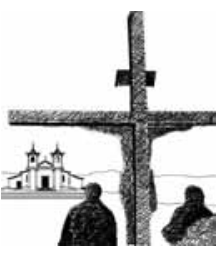

115 
sua forma de aplicação a partir dos seus legislativos (BRASIL, 1988, artigo 18). Isso, em certa medida, acentuou as desigualdades inter e intrarregionais, visto que, como diz Oliveira, na estrutura do federalismo no molde brasileiro, há "uma diferenciação acentuada na distribuição das receitas fiscais, no padrão das políticas públicas e, no caso da educação, grande diversidade na forma e nos meios de provimento desse direito" (OLIVEIRA, 2010, p. 09). Fato que decorre do desenvolvimento desigual dos estados e municípios e da falta de participação da União para garantir a redução das assimetrias por meio da transferência de recursos compatíveis com as necessidades regionais.

Oliveira acrescenta que a federação na República nasce na perspectiva da descentralização e que se trata de uma forma de organização:

[...] capaz de permitir aos entes federados gozar de maior autonomia do que no Império. Entretanto, à maior descentralização corresponde uma maior desigualdade, a menos que o centro exerça um contrapeso no sentido de implementar ações supletivas (OLIVEIRA, 2010, p. 14).

A contradição também se apresenta quando se associa descentralização à democratização. Abrúcio (2010) esclarece que, se de um lado, a primeira abre possibilidade para a efetivação da segunda por aproximar os governantes da população, de outro, complexifica o processo de decisão e sua legitimação, "uma vez que cresce o número de atores e de arenas capazes de definir os rumos da ação coletiva" (ABRÚCIO, 2010, p. 42).

Nesse cenário, a atuação da União na construção do pacto federativo é fundamental. Affonso (1995), ao partir do entendimento que a federação é uma forma de organização territorial do poder, fundada na articulação do poder central com os poderes regional e local e materializada em um conjunto complexo de alianças por meio dos fundos públicos, afirma que o "pacto federativo" se configura justamente por meio dos fundos 
públicos. Além disso, argumenta que nesse sistema, o equilíbrio é fundamental para viabilizar o pacto federativo, a contribuição deveria vir do ente federado responsável pela manutenção das relações, que dispõe de receitas específicas para desempenhar tal função - o governo federal - por meio dos fundos públicos (DALLARI, 1986; AFFONSO, 1995).

Embora com a promulgação da CF/88 tenha havido uma descentralização fiscal em favor dos estados e municípios, vários autores: Affonso (1995), Rezende (1997) e Fiori (1995) evidenciaram em suas pesquisas que a mesma foi acompanhada de aumento significativo da participação dos governos subnacionais nas despesas públicas e da diminuição da participação da União principalmente nos serviços como educação, saúde e saneamento. Além disso, esses autores têm evidenciado que a União recuperou as "perdas" financeiras com a instituição do Fundo Social de Emergência (FSE), posteriormente denominado Fundo de Emergência Fiscal (FEF) com a Desvinculação de Receitas da União (DRU) e com as contribuições sociais e econômicas (ABRÚCIO, 1998; PINTO, 2000).

Na educação, o federalismo se expressa, segundo Abrúcio (2010), na "combinação da descentralização com diretrizes nacionais e cooperação intergovernamental maior" (ABRÚCIO, 2010, p. 40). Corrobora com isso Oliveira ao afirmar que uma compreensão da política educacional passa pelo reconhecimento da existência de uma "tensão entre centralização e descentralização e a forma de colaboração ou relacionamento entre a União e os entes federados" (OLIVEIRA, 2010, p. 14).

O Pacto Federativo em educação se faz necessário mediante a complexidade e diversidade existentes no Brasil entre suas unidades subnacionais. Isso se deve em parte ao modelo de desenvolvimento adotado no país no período compreendido entre os anos de 1950 a 1990. Esse modelo priorizou - em consonância às

4 Referente à Comissão Econômica para a América Latina e o Caribe (Cepal), que foi criada em 1948 pelo Conselho Econômico e Social das Nações Unidas (ECOSOC). É uma das cinco comissões econômicas regionais das Nações Unidas (ONU) criada para monitorar as políticas direcionadas à promoção do desenvolvimento econômico da região latino-americana.

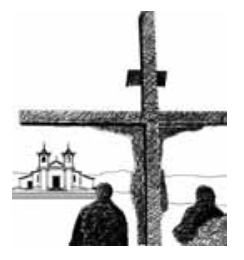

117 
ideias cepalinas ${ }^{4}$ - a equidependência entre as regiões. Acreditavase que assim haveria aumento de produtividade e da renda regional (RODRIGUEZ, 1995).

Como consequência desse modelo, houve o aumento das tensões intra e inter-regionais com concentração de poder decisório em apenas uma das instâncias, nesse caso a União. No entanto, a execução de políticas públicas ficou a cargo dos municípios. Acerca disto Aghón argumenta que:

[...] la descentralización delega a las municipalidades, por lo menos em espíritu, la mayoria de las funciones y pretende hacer de éstas el centro de la vida ciudadana. Así ellas serán las encargadas de la provisión de bienes y servicios tales como los servicios urbanos y las actividades de educación y cordinación com las municipalidades bajo su jurisdicción (AGHÓN, 1995, p. 137).

Desse modo, estamos em face de uma fragmentação comandada por poderes locais em que Estados e municípios atuam de maneira predatória, ou seja, unidades subnacionais que disputam entre si recursos e investimentos. Uma das formas em que isso se traduz são as guerras fiscais, que se caracterizam por serem disputas entre Estados pela via da concessão de incentivos fiscais com a finalidade de atrair investimentos para seu território (SILVA; COSTA, 1997; REZENDE, 1995).

Em razão desse conflito entre os entes federados, são muitos os obstáculos para a efetivação do Pacto Federativo, seja na repartição de recursos ou na implementação de políticas sociais. Para que haja a consecução do pacto, deve haver a ação solidária entre os

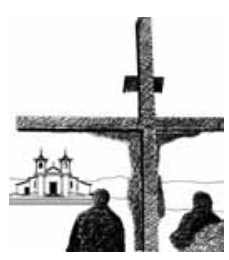
três níveis de governo na formulação e execução dos serviços públicos (SOUZA, 1997).

\section{Diretrizes Nacionais para os Planos de Carreira e Remuneração dos Profissionais do Magistério da Educação Básica}


As Diretrizes Nacionais para os novos PCCRs surgem da necessidade de adequar os novos planos às alterações advindas da Emenda Constitucional n. 53 de 06 de dezembro de 2006, da lei n. 11. 494 de 20 de junho de 2007 e da lei n. 11.738 de 16 de julho de 2008, que criaram e regulamentaram respectivamente o Fundeb e o Piso Salarial Profissional Nacional (PSPN).

No CNE, a elaboração de proposta de reformulação da resolução n. 03/1997 e de novas Diretrizes Nacionais para os PCCRs dos Profissionais do Magistério da Educação Básica ficou sob a responsabilidade de uma comissão especial ${ }^{5}$ constituída para esses fins.

A comissão realizou três audiências públicas nacionais que aconteceram em: São Paulo (16 de outubro de 2008); Olinda (24 de novembro de 2008); e Brasília (05 de dezembro de 2008). Percebemos com isso a exclusão das outras regiões do país como espaço de discussão das propostas de diretrizes, reduzindo as possibilidades de construção de um pacto sobre a carreira do magistério na educação básica no país.

Nessas audiências, foram produzidas cinco versões em forma de minutas do projeto de resolução contendo, sobretudo, matérias abordadas no projeto de lei n. 1.592/2003 do deputado Carlos Abicalil, bem como das contribuições dos próprios conselheiros do CNE e dos participantes das audiências.

De acordo com o parecer da Câmara de Educação Básica do Conselho Nacional de Educação (CNE/CEB) n. 09/2009, a nova resolução prevê em seu artigo $4^{\circ}$ a obrigatoriedade dos entes federados que oferecem qualquer etapa da educação básica, bem como suas modalidades correspondentes, de criarem seus Planos de Carreira para os profissionais do magistério a partir de princípios básicos apontados/contidos na resolução.

Apesar da obrigatoriedade da criação dos planos de carreira, não podemos perder de vista que se trata de uma resolução que

5 A referida comissão foi presidida pelos seguintes conselheiros: César Callegari (presidente); Maria Izabel Azevedo Noronha (relatora); Adeun Hilário Sauer; Clélia Brandão Alvarenga Craveiro e Raimundo Moacir Mendes Feitosa.

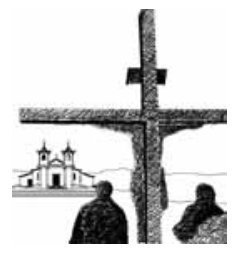

119 
contem diretrizes gerais, ou seja, não se trata de uma medida em que os entes federados estejam obrigados por lei a aderir e seguir integralmente todas as respectivas indicações, posto que iria de encontro ao principio de autonomia desses entes. Dentre os princípios básicos contidos na resolução e que deveriam compor os PCCRs dos estados e municípios brasileiros, subscreve-se: acesso; formação; progressão na carreira e avaliação de desempenho.

No que concerne ao aspecto "acesso", a resolução se respalda na Lei de Diretrizes e Bases da Educação Nacional (LDB), lei n. 9.394 de 20 de dezembro de 1996, mais especificamente em seu artigo 85, que estabelece como forma de acesso à carreira do magistério a prévia aprovação em concurso público de provas e títulos.

As diretrizes sugerem que o acesso à carreira do magistério se dê por meio do concurso público. Isso se relaciona diretamente à qualidade do ensino, visto que por serem submetidos a provas e provas de títulos, os candidatos aprovados podem ser considerados capacitados para as funções.

Em relação ao princípio do acesso à carreira do magistério, observamos que as indicações não são novas, mantendo-se as determinações legais da Constituição Federal de 1988 e da LDB, lei n. 9.394/1996. Apesar do tempo de promulgação dessas leis, vários estados e municípios continuam contratando professores sem concurso público, apoiando-se no argumento da urgência em suprir a falta de professores.

$\mathrm{O}$ artigo $4^{\circ}$ da resolução prevê o incentivo à dedicação exclusiva (DE) do professor e sua respectiva vinculação a uma só unidade escolar com vistas a garantir a qualificação e continuidade do Projeto Político Pedagógico (PPP) da escola. Como forma para a viabilidade desse dispositivo, o referido parecer sugere que sejam criados benefícios salariais diferenciados aos DEs. Trata-se de uma medida inovadora que se acolhida pelos estados e municípios poderá contribuir tanto para qualificar o trabalho do professor quanto para facilitar a organização dos mesmos, tendo em vista que os professores poderão construir vínculos e identidade com o local de trabalho. 
No que se refere ao princípio "formação do professor", a resolução prevê, nos incisos XI, XIV, XV e XVI do artigo $5^{\circ}$, a formação inicial e continuada de forma permanente. Cabe aos entes federados estabelecer incentivos como licença remunerada e programas de qualificação, inclusive em nível de pós-graduação.

$\mathrm{O}$ artigo $5^{\circ}$, inciso XI, prevê ainda, a exemplo da LDB, como forma de prover a formação dos professores, que em exercício, eles tenham tempo reservado durante a jornada de trabalho para o estudo, planejamento e avaliação. São observações que em alguns PCCRs de estados e municípios já vinham sendo contemplados. Citamos, por exemplo, o Estatuto do Magistério do Estado do Pará e do município de Belém, aprovados em 1986 e 1991, respectivamente. Todavia, essas garantias decorreram de reivindicações dos professores e não de orientações do Executivo.

Outro principio que norteia a elaboração das diretrizes referese à "progressão na carreira e à avaliação de desempenho" dos profissionais do magistério. O documento sugere que a avaliação de desempenho se institua de forma plena, de modo a promover a qualidade do processo de ensino-aprendizagem e não como mecanismo de punição aos profissionais.

Ainda sobre a avaliação de desempenho, a resolução estabelece em seu artigo $5^{\circ}$, alínea " $c$ ", que tal avaliação deve ser pautada em dois aspectos complementares: da "objetividade", que considere a escolha de requisitos que possibilitem a análise de indicadores quantitativos e qualitativos; na "transparência”, "que assegura que os resultados da avaliação possam ser analisados pelos avaliados e avaliadores com vistas à superação das dificuldades detectadas para o desempenho profissional ou do sistema".

As diretrizes prevêem também que a avaliação do desempenho seja pautada no princípio de "participação democrática", que se traduzirá na construção coletiva dos processos de avaliação entre os profissionais do magistério e o órgão executivo responsável pelo processo avaliativo. Essas indicações, apesar de em termos teóricos não serem novas, na prática, parecem ainda serem poucos

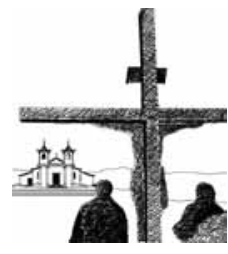


os PCCRs que a contemplam ou que a operacionalizam. Sobre isso, Gatti e Barreto (2009), ao procederem a um levantamento sobre a carreira do magistério em dez estados e trinta municípios brasileiros, revelaram dentre outros pontos que a avaliação por desempenho não apareceu em nenhum deles.

Avaliamos que as diretrizes apresentam-se como "ensaios" de coordenação ou direcionamento de políticas para carreira dos docentes por parte da União. No entanto, tornam-se frágeis ou sem efeito jurídico diante da autonomia dos estados e municípios que podem acatar ou não, sem que isso seja ilegítimo.

Além disso, as diretrizes fixam datas para aprovação dos Planos de Carreira e Remuneração que não foram cumpridas pela maioria dos entes federados. Ademais abrem a possibilidade de um plano unificado dos trabalhadores em educação, mas deixam a critério dos estados e municípios. Como isso representa possibilidade de aumento da folha de pagamento, por certo serão poucos os que seguirão a orientação de incorporação dos demais trabalhadores da educação.

\section{Plano de Cargos, Carreira e Remuneração para o Magistério da Educação Básica da Rede de Ensino do Estado do Pará}

O PCCR do estado do Pará começou a ser elaborado em 2008, por uma comissão formada por representantes da Secretaria de Estado de Educação do Pará (Seduc) e do Sintepp, dando origem a duas propostas: uma proveniente do governo do Estado via Seduc e outra formulada pelo Sintepp. Ambas foram debatidas em audiências públicas na Alepa.

O início das discussões sobre o PCCR, por parte do governo estadual, foi feito por meio do diálogo entre os secretários adjuntos de Logística e Gestão da Seduc, com doze dirigentes das unidades Seduc na escola (USEs) que administram escolas da região metropolitana de Belém e os dirigentes das Unidades 122 Regionais de Educação (UREs), que gerenciam escolas no interior 
do estado. Esses sujeitos representavam a categoria docente de suas respectivas regiões de atuação nos debates promovidos pela Seduc. Nos debates foi apresentada aos profissionais representantes da categoria docente a proposta de PCCR do Executivo estadual.

A proposta do governo apresentava muitos pontos divergentes à proposta formulada pelo sindicato. A proposta do Sintepp previa que todos os trabalhadores da educação da rede estadual do Pará fossem incluídos no PCCR. No entanto, a proposta do governo estadual só incluía no plano, os profissionais do magistério, excluindo cerca de quatorze mil funcionários de escola - auxiliar administrativo; assistente administrativo e operacional; merendeira; porteiro e outros (SINTEPP, 2009).

Outra divergência entre as propostas se refere à valorização dos profissionais da educação. Como a proposta do Executivo estadual contemplava apenas os profissionais do magistério, nada se mencionava a esse respeito na proposta de PCCR. Assim, excluíam-se os demais trabalhadores da educação, entendidos na proposta do sindicato como "todos aqueles profissionais que direta ou indiretamente atuam na escola, seja desenvolvendo as funções do magistério, seja na atividade 'meio', dando suporte administrativo e operacional" (SINTEPP, 2009, artigo 6 ${ }^{\circ}$, inciso I).

A proposta do Sintepp pleiteava que os demais trabalhadores da educação também fossem incluídos não só no PCCR, como também em garantias de valorização profissional. Cabe esclarecermos que o item "valorização" congregava em ambas as propostas questões relativas à remuneração digna, melhoria do desempenho profissional e da qualidade do ensino prestado à população do estado (SINTEPP, 2009, artigo $2^{\circ}$, incisos I a VI).

Sem a inclusão de todos os profissionais da educação estadual no PCCR do Executivo, o avanço na carreira via progressão funcional seria garantido somente aos profissionais do magistério. Na proposta do Sintepp, esse direito seria estendido a todos os trabalhadores da educação, juntamente com a garantia de

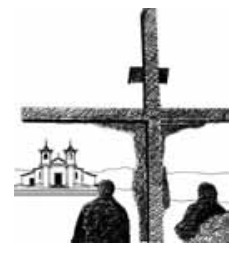


participação na elaboração, execução e avaliação do Projeto Político Pedagógico (PPP) da escola.

Outra dissonância entre governo e sindicato na elaboração do PCCR que merece ser destacada foi o que se refere aos professores enquadrados nas categorias AD1 e AD2 ${ }^{6}$. A proposta do governo previa a criação de uma "classe especial" que agregaria esses profissionais, fato que impossibilitaria a progressão funcional deles devido à sua formação. Com isso, cerca de quatro mil professores seriam prejudicados (SINTEPP, 2009).

A progressão na carreira para os demais profissionais do magistério se daria, na proposta do governo, em doze níveis definidos de "A" a "L" e a evolução seria mediante "critérios de avaliação de desempenho e participação em programas de desenvolvimento profissional" (SINTEPP, 2009). Na contraproposta do Sintepp, essa progressão aconteceria a cada dois anos, de maneira automática e em quinze níveis definidos de " $\mathrm{A}$ " a " $\mathrm{O}$ ". Isso porque no entendimento do sindicato, a avaliação de desempenho, como possível mecanismo de progressão na carreira, poderia se caracterizar em uma forma de punição ao servidor.

A Avaliação de Desempenho Funcional aparece na proposta do governo estadual, artigo 10, entre as alíneas " $a$ " e " $h$ ", como condição necessária ao desenvolvimento na carreira e é definida como:

[...] um processo global e permanente na rede pública de ensino mediante o qual a administração afere a eficiência do servidor, avaliando-o no exercício de suas atribuições mediante critérios objetivos, dentre os quais: assiduidade; pontualidade; participação efetiva na elaboração do PPP

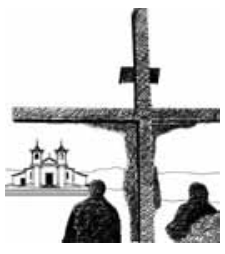

124 e de planejamento pedagógico; aplicação do PPP; produção em cursos de formação continuada; eficiência; responsabilidade; e cumprimento de metas (SINTEPP, 2009).

O Sintepp reivindicou a supressão na íntegra desse artigo

6 Professores que ingressaram na rede estadual apenas com a escolaridade em nível de magistério, mas que atualmente possuem nível superior e continuam enquadrados como profissionais de nível médio. 
por entender que tais critérios possuíam caráter punitivo e não formativo, visto que criariam barreiras para a progressão funcional dos trabalhadores da educação básica da rede estadual. A inclusão de medidas de avaliação por desempenho ainda não eram frequentes nos Planos de Carreira e Remuneração mais antigos, como revelam Gatti e Barreto (2009) no estudo sobre os professores. Porém, nos mais recentes, são comuns e decorrem de orientações teóricas em nível macro. Uma das discussões em favor da incorporação dessas medidas decorre da proposição de haver relação entre qualidade de ensino e desempenho dos professores, ou seja, a melhoria da qualidade de ensino demandaria mudanças no desempenho dos professores, introduzindo-se mecanismos de mercado com vistas no resultado. Uma das mudanças seria responsabilizá-los pelos resultados dos alunos e da escola.

Morduchowicz, em estudo realizado sobre carreira e salários docentes em alguns países da América Latina, observou em relação à avaliação por desempenho que: "quando existe, constitui mera formalidade. Não há sistemas estruturados de avaliação de desempenho docente" (MORDUCHOWICZ, 2003, p. 20). Sobre essa constatações incidem as maiores críticas sobre a estrutura de remuneração dos professores que não faz distinção entre desempenhos "bons", "maus", "medíocres".

O tema é polêmico e a tão propalada relação entre qualidade de ensino e desempenho docente não se manifesta de forma nítida nos estudos. Além disso, a avaliação por desempenho se revela como mecanismo revestido de conflitos de interesses entre os gestores dos sistemas educativos e os professores (ISORÉ, 2010)

Quanto à progressão na carreira, observamos nas duas propostas, que ela poderia se efetivar em dois níveis: horizontal ${ }^{7}$ ou vertical ${ }^{8}$. Em relação à progressão dos professores AD1 e AD2, a proposta do governo previa que eles, por fazerem parte da

7 Progressão horizontal é aquela que se dá por classes, que é o conjunto de cargos de mesma natureza funcional, mesma escolaridade e/ ou titulação e de mesmo grau de responsabilidade. 8 Progressão vertical é aquela que se dá por níveis, que se trata do símbolo alfabético indicativo do valor do vencimento-base fixado para a classe, que representa o crescimento funcional do servidor no plano e/ou na carreira.

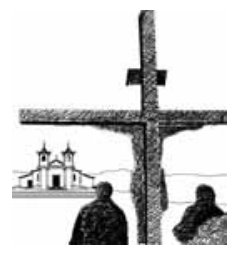

125 
chamada "classe especial", teriam direito somente à progressão horizontal (artigo 14, $\$ 1^{\circ}$ ). OSintepp, em sua proposta, reivindicava que esse item fosse suprimido, pois se permanecesse, impediria os professores com magistério de nível médio de ascenderem na carreira mediante sua escolaridade, ou seja, mesmo concluindo o curso de nível superior, não garantiriam sua progressão funcional.

$\mathrm{O}$ artigo $14, \S 2^{\circ}$, da proposta do governo afirmava que

os processos de progressão funcional só seriam iniciados após autorização expressa da Secretaria de Planejamento, Orçamento e Finanças (SEPOF), a qual indicará a disponibilidade orçamentária específica para este fim (PARÁ, 2008).

Mais uma vez o Sintepp sugeriu a supressão desse parágrafo, alegando que sua manutenção deixaria os trabalhadores à mercê da vontade política do governo, que sempre alegava em negociações com o sindicato, não dispor de recursos para valorização dos trabalhadores da educação.

Em relação à progressão funcional horizontal (artigo 15, §2 e vertical (artigo 18), a proposta do governo estadual previa que essas se dariam somente mediante disponibilidade orçamentária. O Sintepp pedia em sua proposta a supressão desses itens por compreender que o Executivo tem obrigação de assegurar a progressão funcional horizontal a todos os trabalhadores, desde que eles tenham cumprido os prerrequisitos de merecimento exigidos em lei. Essa medida condiciona a progressão dos professores à previsão orçamentária, o que demanda dos professores organização permanente para prevê o número e valores necessários e incluí-los no orçamento anual de modo a garantir que não haja impedimento de progressão por falta de previsão orçamentária.

O artigo 43 da proposta do governo sugeria que "as despesas decorrentes da aplicação desta Lei correrão à conta da dotação orçamentária proveniente do FUNDEB" (PARÁ, 2008). A proposta do Sintepp indicava que esse artigo fosse suprimido, 
pois reduziria para $20 \%$ os investimentos em educação. Isso porque a subvinculação ao fundo não incorpora todos os recursos vinculados à educação (os impostos próprios dos municípios não fazem parte do Fundeb) e o percentual é inferior ao que determina a Constituição Federal de 1988.

O processo de aprovação do PCCR da rede estadual do Pará foi tumultuado, pois houve resistência do Legislativo estadual em acatar as mudanças sugeridas pelo Sintepp nos artigos considerados polêmicos. Diante disso, no dia 07 de maio de 2010, os professores da rede estadual de ensino paralisaram suas atividades docentes por meio de greve. Eles reivindicavam: a aprovação imediata do PCCR; aumento salarial; melhores condições de trabalho; efetivação da gestão democrática nas escolas. A greve deixou 800 mil alunos sem aulas e cerca de $84 \%$ das escolas estaduais aderiram ao movimento, que durou 26 dias, finalizando após assinatura de um acordo entre o sindicato e a Alepa. Na assinatura do acordo, houve a aceitação por parte dos deputados de itens reivindicados pelo Sintepp para o PCCR.

No dia 15 de junho de 2010, os deputados aprovaram por unanimidade o projeto do PCCR dos servidores estaduais da educação, que teve por relator o deputado Marcio Miranda (Partido Democratas - DEM). No plano aprovado, foram incluídas nove emendas acordadas entre o Sintepp e o governo estadual.

O PCCR foi sancionado no dia 02 de julho de 2010, sem vetos, pela governadora Ana Júlia Carepa (Partido dos Trabalhadores - PT) através da lei n. 7.442 de 2010. O plano deveria começar a vigorar em outubro de 2010, porém como se tratava de ano eleitoral, a efetivação ficou para o ano seguinte, 2011.

A lei n. 7.442 de 2010 congregou os seguintes pontos referentes à proposta do sindicato: inclusão de todos os trabalhadores da educação; definição de quem são e o que fazem os trabalhadores da educação; estabelecimento dos procedimentos de avaliação que deverão ser regulamentados por lei específica; criação de Comissão Permanente de Avaliação de Desempenho Funcional;

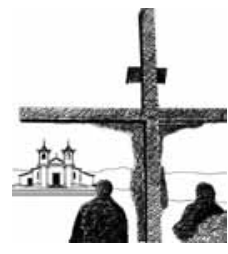


determinação de que a progressão horizontal funcional se dará de forma alternada, ora automática, ora mediante avaliação de desempenho a cada interstício de três anos; definição das vantagens salariais com acréscimo de $50 \%$ para o servidor que exercer atividades na Superintendência do Sistema Penitenciário do Estado (Susipe) e na Fundação da Criança e do Adolescente do Pará (Funcap), e 100\% para servidor que exercer função no Sistema de Organização Modular do Ensino (Some); estabelecimento do regime de 40 horas semanais para os professores fora da regência de classe; determinação da nomenclatura de especialista em educação para o cargo de técnico em educação com flexibilização da jornada de trabalho em 30/40 horas; definição que as despesas decorrentes da aplicação do PCCR não virão das dotações orçamentárias pertencentes ao Fundeb, e sim daquelas destinadas à Manutenção e Desenvolvimento do Ensino (MDE).

De certa forma, consideramos que o PCCR aprovado subscrevese como um plano de construção coletiva e que contemplou a maioria das reivindicações dos trabalhadores da educação estadual do Pará. Notamos ainda, que o PCCR da rede estadual de educação foi norteado em alguns pontos pelas Diretrizes Nacionais aqui abordadas, principalmente no item que se refere à avaliação de desempenho.

\section{Considerações finais}

A concepção de políticas educacionais deve perpassar a instituição de espaços políticos de construção coletiva e democrática. Contudo, observamos que no processo de elaboração

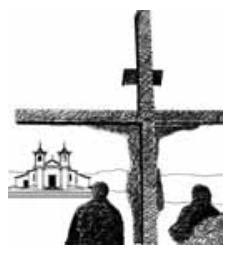
das diretrizes, as demais regiões do país não foram escolhidas como espaço de debate e construção das mesmas. Assim, uma relação entre os entes federados que não contemple todas as unidades subnacionais na concepção e elaboração de suas próprias políticas não se configura como tão coletiva e democrática e vai na contramão da efetivação de pacto entre os entes federados. 
Como sinalizamos no desenvolvimento deste texto, as Diretrizes Nacionais para os PCCRs não figuram como uma obrigação legal. Devemos considerar ainda que as unidades subnacionais são autônomas politicamente, podendo aderir ou não a tais diretrizes, ou seja, não há nenhuma garantia de que os aspectos precípuos à valorização dos profissionais do magistério contidos nas diretrizes sejam efetivamente contemplados nos planos dos Estados, dos municípios e do Distrito Federal.

Ainda assim, reconhecemos que a criação de Diretrizes Nacionais para subsidiar a elaboração dos PCCRs se constitui em relativo esforço da União em prover os novos planos com princípios que balizem a valorização dos profissionais do magistério. Todavia, a mera definição de diretrizes sem assessoramento técnicofinanceiro do ente federado proponente, neste caso, a União, que constitucionalmente exerce essa função supletiva, não garante que a valorização docente propalada nessas diretrizes se efetive na implementação das políticas para esse fim. Portanto, só a definição de diretrizes, sem a cooperação principalmente financeira para que haja melhorias salariais, condições dignas de trabalho (com todos os insumos necessários), formação inicial e continuada, não se constitui como efetivação do pacto entre os entes federados.

Avaliamos que as Diretrizes Nacionais foram medidas importantes para a consolidação da carreira do magistério, mas em função da ausência de coordenação da União de uma política nacional para o magistério - que não apenas diga o que tem que ser feito, mas que colabore para sua efetivação, disputando politicamente e/ou colaborando financeiramente -, tornam-se frágeis diante do quadro de acentuadas desigualdades regionais.

No que se refere à aprovação do PCCR do Estado do Pará, é válido ressaltar que os nove itens que compunham a proposta do sindicato, descritos anteriormente neste texto, foram incluídos no produto final, a lei n. 7.442 de 2010. Consideramos isso como um ponto positivo do processo de elaboração. No entanto, é preciso situar o contexto em que essas reivindicações foram atendidas, pois

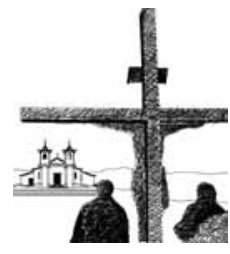


a aprovação do PCCR aconteceu em ano de eleições, o que favoreceu o uso de medidas populistas por parte do governo estadual. Isso fica claro ao atentarmos para a nomenclatura do plano que trata "dos profissionais da educação" como um todo, mas que em seu teor apenas versa sobre os profissionais do magistério.

Outro aspecto que também merece atenção é o fato de mesmo que o PCCR do Estado do Pará tenha levado em consideração em seu produto final algumas determinações das Diretrizes Nacionais, certos aspectos apontados por este documento como negativos prevaleceram no referido plano, por exemplo: os instrumentos que podem vir a ser punitivos na progressão funcional dos profissionais. Dentre eles, citamos critérios presentes na avaliação de desempenho como assiduidade, pontualidade, eficiência, responsabilidade e cumprimento de metas.

Ante o exposto, é necessário considerarmos que a implementação de políticas públicas no Estado brasileiro, em que os entes federados gozam de relativa autonomia, não deve e não se dá de maneira uniforme e/ou homogênea e não têm os mesmos efeitos em todas as unidades subnacionais. Contudo, levando-se em consideração que as discussões em torno da instituição de um sistema nacional de educação medeiam as questões relacionadas à organização federativa do Brasil, também não se pode deixar de vislumbrar a necessidade da colaboração entre os mesmos entes federados não só para a implementação de tais políticas, mas também em sua elaboração com vistas à efetivação de fato do pacto federativo.

Por fim, consideramos que no caso do estado do Pará, a elaboração do PCCR dos profissionais da educação foi um processo de diálogo que apesar das peculiaridades mencionadas,

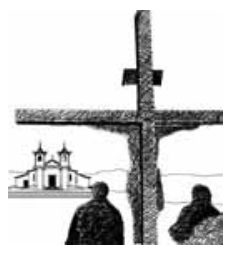
se constituiu em esforço para construir políticas públicas balizadas pela participação dos agentes imbricados por elas, bem como da sociedade de modo geral. 


\section{Referências}

ABRÚCIO, F. L. A dinâmica federativa da educação brasileira: diagnóstico e propostas de aperfeiçoamento. In: OLIVEIRA, R. P.; SANTANA, W. Educação e federalismo no Brasil: combater as desigualdades, garantir a diversidade. Brasília: UNESCO, 2010.

AFFONSO, R. de B. A. A federação no Brasil: impasses e perspectivas. In: AFFONSO, R. de B. A.; SILVA, P. L. B. A federação em perspectiva: ensaios selecionados. São Paulo: FUNDAP, 1995.

AGHÓN, G. Descentralización fiscal em América Latina: algunas experiências. In: AFFONSO, R. de B. A.; SILVA, P. L. B. A federação em perspectiva: ensaios selecionados. São Paulo: FUNDAP, 1995.

CONSELHO NACIONAL DE EDUCAÇÃO. Resolução n. 2/2009 e Parecer CNE/CEB n. 09/2009. Diretrizes Nacionais para os Novos Planos de Carreira e de Remuneração para o Magistério dos Estados, do Distrito Federal e dos Municípios. Brasília: MEC, 2009.

FIORI, J. L. O federalismo diante do desafio da globalização. In: AFFONSO, R. de B. A; SILVA, P. L. B. A federação em perspectiva: ensaios selecionados. São Paulo: FUNDAP, 1995.

ISORÉ, M. Evaluación docente: prácticas vigentesen los países de la OCDE y uma revisión de la literatura. Documentos, n. 46. PREALChile, 2010.

MORDUCHOWICZ, A. Carreiras, incentivos e estruturas salariais docentes. Programa de promoção da reforma educativa na América Latina e Caribe. (PREAL), Brasil, Rio de Janeiro, n. 23, jun. 2003.

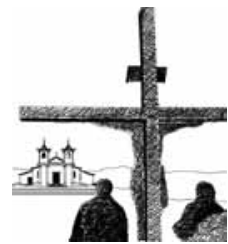


OLIVEIRA, R. P.; SANTANA, W. Educação e federalismo no Brasil: combater as desigualdades, garantir a diversidade. Brasília: UNESCO, 2010.

PARÁ. SECRETARIA DE ESTADO DE EDUCAÇÃO. Proposta de Plano de Carreira, Cargos e Remuneração dos Professores. Belém: 2008.

PARÁ, Assembléia Legislativa do Estado. Lei n. 7.442 de 02 de julho de 2010. Dispõe sobre o Plano de Cargos, Carreira e Remuneração dos Profissionais da Educação Básica da Rede Pública de Ensino do Estado do Pará e dá outras providências. Diário Oficial do Estado do Pará, Belém, 12 jul. 2010.

PINTO, J. M. de R. Recursos para educação no Brasil no contexto das finanças públicas. Editora: Plano, 2000.

REZENDE, F. O financiamento das políticas públicas: problemas atuais. In: DINIZ, E.; AZEVEDO, S. Reforma do estado e democracia no Brasil: dilemas e perspectivas. Brasília: Editora Universidade de Brasília, 1997.

RODRIGUES, V. Federalismo e interesses regionais. In: AFFONSO, R. de B. A.; SILVA, P. L. B. A federação em perspectiva: ensaios selecionados. São Paulo: FUNDAP, 1995.

SILVA, P. L. B. A natureza do conflito federativo no Brasil In: DINIZ, E.; AZEVEDO, S. Reforma do estado e democracia no Brasil: dilemas e perspectivas. Brasília: Editora Universidade de Brasília, 1997.

SILVA, P. L. B.; COSTA, V. L. C. Descentralização e crise da federação. In: DINIZ, E. AZEVEDO, S. Reforma do estado e democracia no Brasil: dilemas e perspectivas. Brasília: Editora Universidade de Brasília, 1997. 
SOUZA, C. Constitutional engineering in Brazil: the politics of federalism and decentralization. Londres/Nova York: Macmillan/St. Martin's Press, 1997. 211 p.

SINTEPP - SINDICATO DOS TRABALHADORES EM EDUCAÇÃO PÚBLICA DO PARÁ. Proposta de Plano de Carreira, Cargos e Remuneração dos Professores, Belém, 02 de dezembro de 2009.

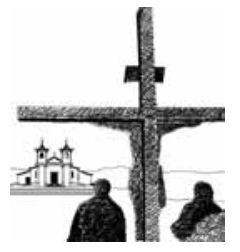




\title{
Federative Pact and Career Plan, Career and Remuneration of Education Professionals: the case of Pará
}

\begin{abstract}
:
Nowadays there is a return to the debates about the federative mode the possibilities and configurations of pact among the federative entities when it comes to providing public education. Taking into account these bases, the text aims at analyzing the elaboration and negotiation process related to the Office, Career, and Remuneration Plan (PCCR) of Pará States Mastership. The analysis takes place comparing National Policies for PCCR made by the National Education Council (CNE), and Pará's Union of Public Education Workers (Sintepp) Plan's proposal, government's proposal and the final result of these ones, the law $n$. $7.447 / 10$. We conclude that the definition of policies for PCCR elaboration is not enough for putting into effect the federative pact, and that the struggle and organization of teachers, trough their Union on the Pará State's PCCR elaboration process was important for assuring progress of the so called mastership valuation.
\end{abstract}

Keywords: Federative pact; basic education; office, career and remuneration plan.

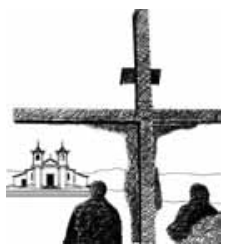

